\title{
Design of X-Band MEMS Microstrip Shunt Switches
}

\author{
Jad B. Rizk, Student Member IEEE, Jeremy B. Muldavin, Student Member IEEE, \\ Guan-Leng Tan, Student Member IEEE and Gabriel M. Rebeiz, Fellow IEEE \\ Radiation Laboratory, Department of Electrical Engineering and Computer Science, \\ University of Michigan, Ann Arbor, Michigan, 48109-2122, USA. \\ jrizk@engin.umich.edu,muldavin@engin.umich.edu, gtan@engin.umich.edu, \\ rebeiz@umich.edu.
}

\begin{abstract}
This paper presents the design and performance of X-band MEMS switches built in microstrip technology. The switches result in an insertion loss of less than $0.1 \mathrm{~dB}$ and a small isolation bandwidth, less than $10 \%$, and are limited by the radial stubs bandwidths. The isolation value is also not dependent on the down-state capacitance of the switch. The isolation bandwidth (less than $-20 \mathrm{~dB}$ isolation) is improved to $8-13 \mathrm{GHz}$ with the use of a $\pi$-network and two MEMS switches. The up-state insertion loss of the $\pi$ switch is less than $0.25 \mathrm{~dB}$. The paper demonstrates that the performance of microstrip switch circuits without via-holes is dominated by the shorting (radial) stubs, and careful design must be done to result in an acceptable bandwidth of operation.
\end{abstract}

Keywords-MEMS, low-loss, micromachining, switches, microwave, millimeter-wave.

\section{INTRODUCTION}

Micro-Electro-Mechanical-Systems (MEMS) electrostatically actuated reflective switches for low-loss microwave and mm-wave applications have been recently demonstrated [1], [2], [3], [4]. MEMS switches are composed of a thin metal membrane (or beam) which can be electrostatically actuated to the RF line using a DC bias voltage. The MEMS switch has very little DC power consumption (1-3 nJ during the switching process), allows for large down-state to upstate capacitance ratios $\left(C_{d} / C_{u}=20-100\right)$, has very low intermodulation products, and can be fabricated on almost any substrate. Several disadvantages include slow switching speeds $(2-10 \mu \mathrm{s})$ and high actuation voltages $(15-80 \mathrm{~V})$.

This paper focuses on the design and measurement of microstrip shunt capacitive switches. This is a departure from the current literature which is on coplanar-waveguide (cpw) switches. The microstrip designs offer easier biasing of the individual switches, especially if a large number is used. However, it requires via-hole technology for obtaining a wideband short circuit to ground. This paper demonstrates that a single MEMS microstrip switch has a very small isolation bandwidth. However, it is possible to obtain wideband performance using two microstrip switches connected in a $\pi$ configuration.

\section{SINGLE MEMS SHUNT SWITCHES: DESIGN AND MEASUREMENTS}

Fig. 1 shows a microstrip shunt capacitive MEMS switch which is connected to a $\lambda / 4$ resonant stub. When the switch is in the up state position, the up-state capacitance is negligible (40-100 fF) and the switch has a very low insertion loss (less than $0.1 \mathrm{~dB}$ ). When the switch is in the down-state position, the radial stub is connected to the microstrip line through the down-state capacitance $\left(C_{d}=2-5 \mathrm{pF}\right.$ depending on the size of the switch) and the switch isolation is limited by the bandwidth of the radial stub.

The resonant frequency is dependent on the switch down-state capacitance and inductance values (Fig. 2). The response is very narrowband, and is given by the radial stub bandwidth. The switch inductance $(10-20 \mathrm{pH})$ has a small effect since the stub inductance is around $400-500 \mathrm{pH}$. However, the switch down-state capacitance results in a considerable change in the resonant frequency for low capacitance values (1-3 $\mathrm{pF}$ ) and in less change for high capacitance values (3-6 pF). This is expected due to the series combination between the down-state capacitance and the radial stub. Note that the isolation value is independent of the down-state capacitance and is limited to $35 \mathrm{~dB}$ by the series resistance of the 
switch and the radial stub (around $0.35 \Omega$ ).

In this design, the stub is $1,950 \mu \mathrm{m}$ long and is designed to resonate at $8.3 \mathrm{GHz}$, with an equivalent series $\mathrm{LC}$ circuit of $\mathrm{L}=430 \mathrm{pH}$ and $\mathrm{C}=850 \mathrm{fF}$ (obtained using Libra). When the switch is connected to the stub with an expected capacitance of $C_{d}=1.8 \mathrm{pF}$, the effective capacitance of the switch/stub combination decreases to $580 \mathrm{fF}$, resulting in a resonant frequency of $10 \mathrm{GHz}$.

The switches are fabricated on a $400 \mu \mathrm{m}$ thick high-resistivity silicon wafer (2,000-3,000 $\Omega . c m)$. The microstrip lines are deposited using $2 \mu \mathrm{m}$ thick gold and result in an attenuation of $0.5 \mathrm{~dB} / \mathrm{cm}$ at $10 \mathrm{GHz}$. The MEMS bridge is fabricated using $1.5 \mu \mathrm{m}$ sputtered gold layer and is suspended $1.5 \mu \mathrm{m}$ above the microstrip line. The interlayer dielectric is $1500 \AA$ of silicon nitride $\left(\epsilon_{r}=7.6\right)$. The pull down voltage was more than $40 \mathrm{~V}$ since the MEMS bridges were slightly curved up.

Fig. 3 presents measurements done on a single microstrip switch in the up and down-state position. The reflection coefficient in the up-state is less than $-25 \mathrm{~dB}$ from 8 to $12 \mathrm{GHz}$ equivalent to an up-state capacitance of $40 \mathrm{fF}$. In fact, the switch is matched by the small sections of narrow microstrip line under the bridge which acts like an inductance. The down-state resonance occurs at $9.5 \mathrm{GHz}$ for a stub length of $1,950 \mu \mathrm{m}$ and a down-capacitance of $2.5 \mathrm{pF}$ $(\mathrm{L}=10 \mathrm{pH})$, and results in a $10 \%$ isolation bandwidth at $-20 \mathrm{~dB}$. The measured loss in the up-state position is less than $0.1 \mathrm{~dB}$ at $10 \mathrm{GHz}$. The reference planes are $250 \mu \mathrm{m}$ away from the bridge. Also the isolation bandwidth can be increased by using two stubs connected to the two edges of the MEMS bridge. In this case the $-20 \mathrm{~dB}$ isolation bandwidth is increased to $18 \%$. The penalty paid is an increase in the size of the switch on the $\mathrm{Si} / \mathrm{GaAs}$ wafer.

\section{III. $\pi$ MEMS SHUNT SWITCHES: DESIGN AND MEASUREMENTS}

The bandwidth of the MEMS microstrip switch can be significantly improved if a $\pi$-circuit is used (Fig. 4) . The circuit consists of two MEMS switches connected by a short high-impedance transmission line. The $\pi$-circuit does two functions: First, it provides a good match in the up-state position $\left(S_{11} \leq\right.$ $-20 \mathrm{~dB}$ ) over a wide bandwidth. Second, one can design the stub lengths so as to result in a wide isolation bandwidth. Fig. 5 shows the response of two $\pi$ designs, with $C_{u}=40 \mathrm{fF}, \mathrm{L}=10 \mathrm{pH}, C_{d}=1.8 \mathrm{pF}$, and with either equal stub lengths on both switches $(1,950 \mu \mathrm{m})$ or with different stub lengths $(1,800 \mu \mathrm{m}$ and $2,300 \mu \mathrm{m})$. The mid-section impedance is $60 \Omega$
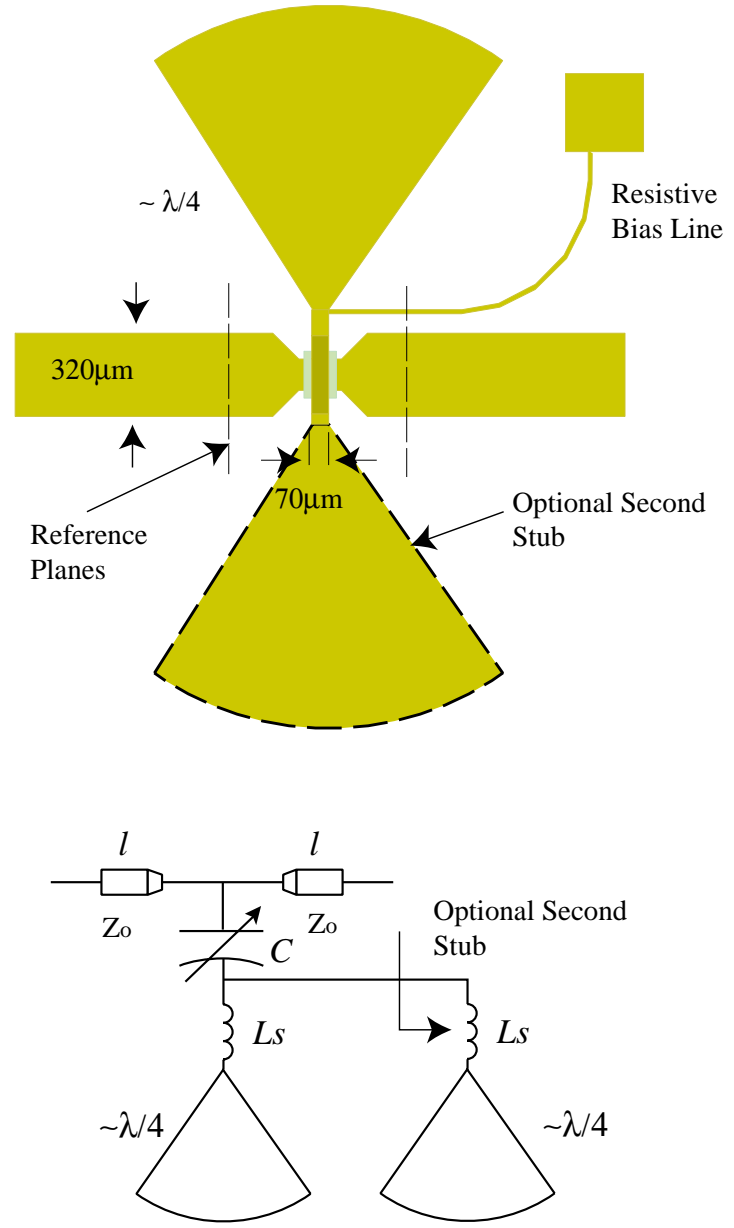

Fig. 1. Microstrip shunt capacitive MEMS switch and its equivalent circuit.

with a length of 1,000 $\mu \mathrm{m}$. The different stub lengths result in an "elliptic" low-pass filter response with a ripple of less than $-30 \mathrm{~dB}$ over $8.5-11.3 \mathrm{GHz}$ bandwidth.

Fig. 6 presents measurements for a $\pi$-circuit with stub lengths of 1,800 and $2,300 \mu \mathrm{m}$. The $-20 \mathrm{~dB}$ isolation bandwidth is from $7.8 \mathrm{GHz}$ to $13.1 \mathrm{GHz}$, and is much wider than the single stub measurements. The up-state reflection coefficient is around $-20 \mathrm{~dB}$ over the entire frequency range $7-15 \mathrm{GHz}$. The measured loss is less than $0.25 \mathrm{~dB}$. The reference planes are $250 \mu \mathrm{m}$ away from the bridge. The measurements, while still excellent, do not agree with the model probably due to different down-state capacitance values.

\section{REFERENCES}

[1] C. Goldsmith and J. Randall and S. Eshelman and T. H. Lin and D. Dennistor and S. Chen and B. Norvell, "Char- 


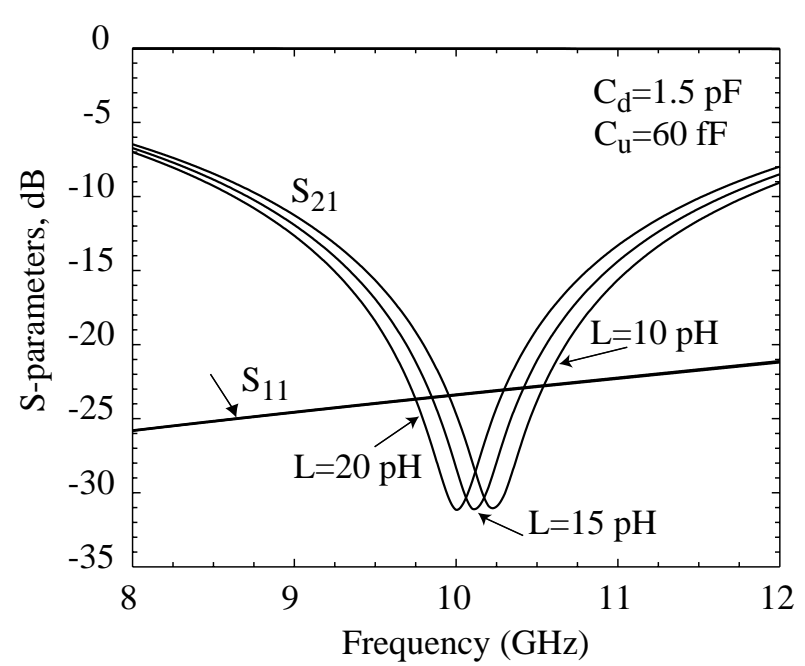

(a)

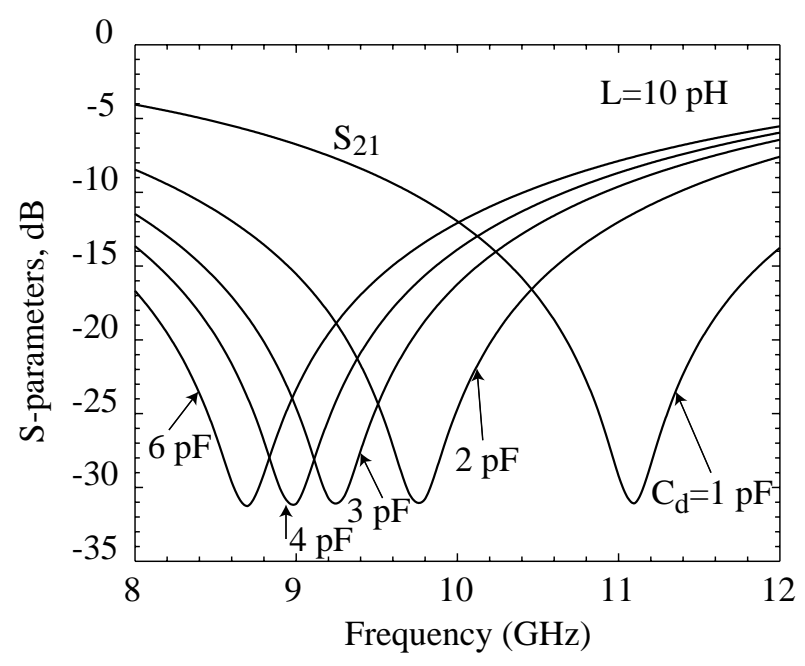

(b)

Fig. 2. Modeled microstrip shunt switch response: (a) effect of L (b) effect of $C_{d}$. $S_{11}$ in the up-state position, $S_{21}$ in the down-state position.

acteristics of Micromachined Switches at Microwave Frequencies," 1996 IEEE MTT-S Int. Microwave Symp. Dig., pp. 1141-1144, San Francisco, CA, June 1996.

[2] Yao, J. J. and M. F. Chang, "A Surface Micromachined Miniature Switch for Telecommunications Applications with Signal Frequencies From DC up to $4 \mathrm{GHz}, " 1996$ Int. Conf. On Solid-State Sensors and Acutators Dig., pp. 384-387, Stockholm, Sweden, June 1996.

[3] J. B. Muldavin and G. M. Rebeiz, "High isolation MEMS shunt switches; Part 1: Modeling," IEEE Trans. Microwave Theory Tech., vol. 48, pp. 1045-1052, June 2000.

[4] J. B. Muldavin and G. M. Rebeiz, "High isolation MEMS shunt switches; Part 2: Design," IEEE Trans. Microwave Theory Tech., vol. 48, pp. 1053-1056, June 2000.

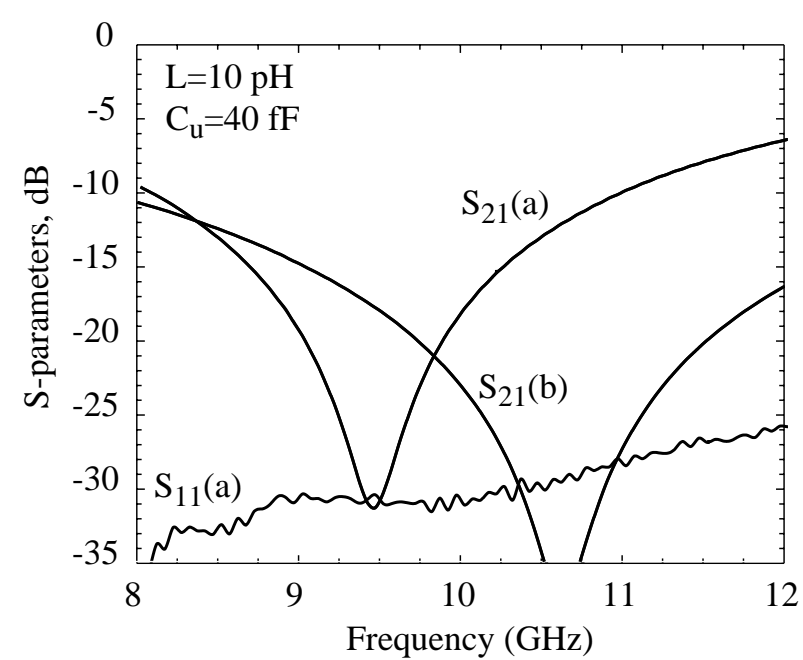

Fig. 3. Measured S-parameters of a single microstrip switch: (a) with one radial stub of $1,950 \mu \mathrm{m}$ in up and down-state positions $\left(C_{d}=2.5 \mathrm{pF}\right)$ (b) two radial stubs of $2,400 \mu \mathrm{m}$ in the down position $\left(C_{d}=1.4 \mathrm{pF}\right)$.
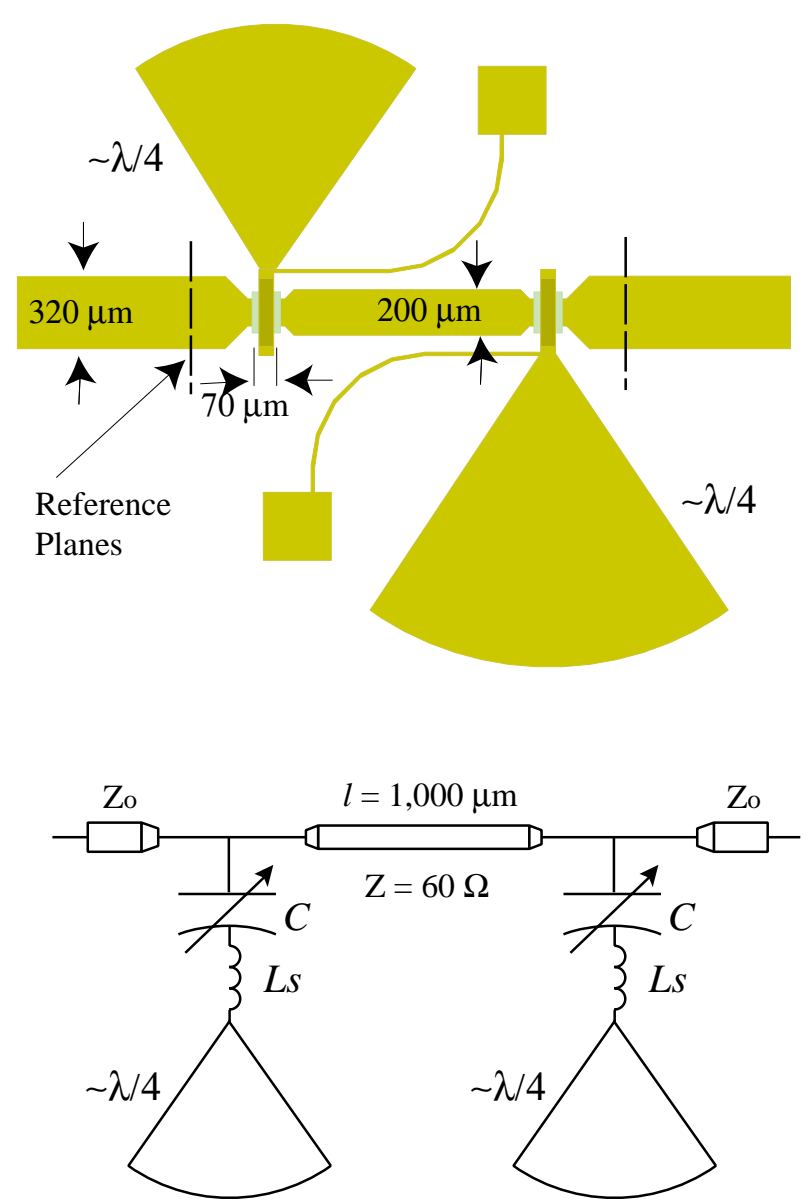

Fig. 4. $\pi$-circuit with microstrip shunt capacitive MEMS switches, and its equivalent circuit. 


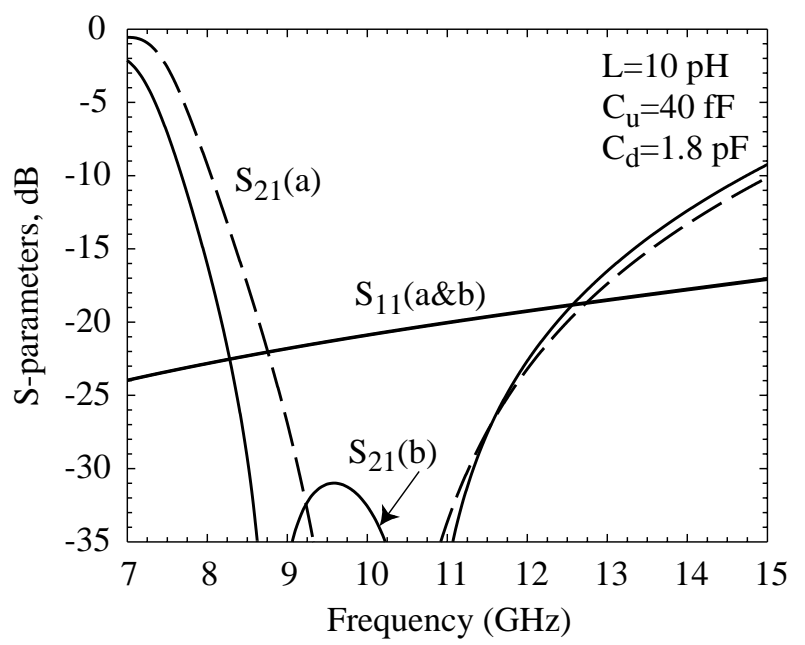

Fig. 5. Modeled $\pi$-circuit shunt switches with (a) two stubs of $1,950 \mu \mathrm{m}$ and, (b) one stub of $1,800 \mu \mathrm{m}$ and one stub of $2,300 \mu \mathrm{m}$.

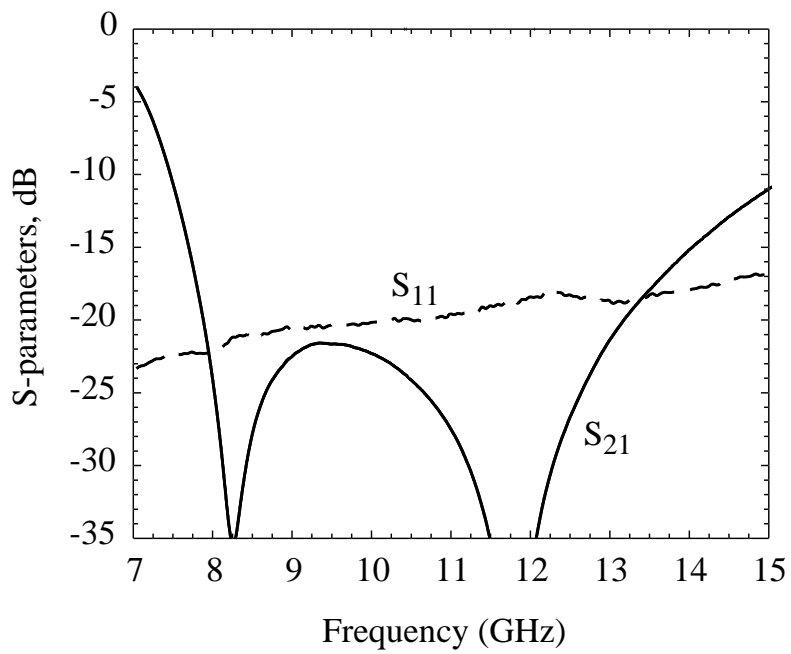

Fig. 6. Measured S-parameters $\pi$-circuit in up and down positions for stub lengths of $1,800 \mu \mathrm{m}$ and $2,300 \mu \mathrm{m}$. 